\title{
Las reformas borbónicas como categoría de análisis en la historiografía institucional, económica y fiscal sobre Nueva España: orígenes, implantación y expansión*
}

ERNEST SánCHEZ SANTiRó

\begin{abstract}
Profesor del Instituto de Investigaciones Dr. José María Luis Mora (México). Correo electrónico: esanchez@institutomora.edu.mx. El autor es doctor en Geografía e Historia de la Universidad de Valencia (España) y forma parte del Sistema Nacional de Investigadores. Entre sus publicaciones recientes tenemos: "Constitucionalizar el orden fiscal en Nueva España: de la Ordenanza de Intendentes a la Constitución de Cádiz (1786-1814)" en Historia Mexicana Vol. LXV: 1, Fasc. 257 (2015) y "El orden jurídico de la fiscalidad en la Real Hacienda de Nueva España: una análisis a partir de la calidad, el estado y la clase de los contribuyentes" en Espacio, Tiempo y Forma. Serie IV Historia Moderna Fasc. 27 (2014). Entre sus temas de interés están historia fiscal de Nueva España y México, siglos XVIII-XIX y desempeño económico de Nueva España y México, siglos XVIII-XIX
\end{abstract}

\footnotetext{
Recibido: 2 de enero de 2016

Aprobado: 14 de marzo de 2016

Modificado: 3 de abril 2016

Artículo de investigación científica
}

DOI: http://dx.doi.org/10.15648/hc.29.2016.3

\footnotetext{
* $\quad$ Este artículo forma parte del proyecto: “Guerra y Hacienda: crisis y transformación de la Real Hacienda de Nueva España en la guerra de Independencia (1810-1821). Proyecto de Ciencia Básica CONACYT núm. 153670", financiado por el Consejo Nacional de Ciencia y Tecnología-CONACYT (México).

Quiero agradecer la ayuda documental de José Luis Galván y Rodrigo Gordoa.

Esta publicación está bajo una licencia Creative Commons Reconocimiento-NoComercial 4.0.
} 
Las reformas borbónicas como categoría de análisis en la historiografía institucional, económica y fiscal sobre Nueva España: orígenes, implantación y expansión

\title{
Resumen
}

Este artículo propone una reconstrucción del origen, características y expansión de la categoría historiográfica "reformas borbónicas" en los campos de la historia institucional, económica y fiscal dedicados a Nueva España. Si bien se efectúa un recorrido que arranca con la historiografía mexicana decimonónica, el trabajo se centra en las aportaciones realizadas por varios historiadores de Europa, Estados Unidos e Hispanoamérica en torno a dicha categoría. Asimismo, se ocupa de su implantación y expansión en la historiografía mexicana a partir de la década de 1970.

Palabras clave: Reformas borbónicas, historiografía, Nueva España, historia institucional, económica y fiscal.

The Bourbon reforms as a category of analysis in the institutional, economic and fiscal historiography of New Spain: origins, implementation and expansion

\begin{abstract}
This article proposes a reconstruction of the origin, characteristics and expansion of the historiographical category "Bourbon reforms" in the fields of institutional, economic and fiscal history dedicated to New Spain. While a journey that starts with the nineteenth-century Mexican historiography is done, the work focuses on the contributions made by several historians of Europe, United States and Latin America around that category. It also deals with the implementation and expansion in Mexican historiography from the 1970 s.
\end{abstract}

Key words: Bourbon Reforms, historiography, New Spain, institutional, economic and fiscal history.

As reformas borbónicas como categoria de análise na historiografía institucional, econômica e promotora sobre Nova Espanha: origens, implantação e expansão

\section{Resumo}

Este artigo propõe uma reconstrução da origem, características e expansão da categoria 
historiográfica "reformas borbónicas" nos campos da história institucional, econômica e fiscal dedicados a Nova Espanha. Conquanto efetua-se um percurso que arranca com a historiografía mexicana decimonónica, o trabalho se centra nas contribuições realizadas por vários historiadores de Europa, Estados Unidos e Hispanoamérica em torno de dita categoria. Assim mesmo, ocupa-se de sua implantação e expansão na historiografía mexicana a partir da década de 1970.

Palavras-chave: Reformas borbónicas, historiografía, Nova Espanha, história institucional, econômica e fiscal.

Les réformes bourboniennes comme catégorie d'analyse dans l'historiographie institutionnelle, économique et fiscale de la Nouvelle Espagne: Origines, implantation et expansion

\section{Résumé}

Cet article propose une reconstruction de l'origine, les caractéristiques et l'expansion de la catégorie historiographique « Réformes Bourboniennes» dans les domaines de l'histoire institutionnelle, économiques et fiscale sur la Nouvelle Espagne. Certes, le parcours commence par l'historiographie Mexicaine du dix-neuvième siècle, ce travail met l'accent sur les contributions réalisées par plusieurs historiens de l'Europe, les EtatsUnis et l'Amérique latine. L'article s'occupe d'avantage, de l'implantation et l'expansion de ces réformes dans l'historiographie mexicaine à partir de la décennie de 1970.

Mots clés: Réformes bourboniennes, historiographie, Nouvelle Espagne, histoire institutionnelle, économique et fiscale.

\section{INTRODUCCIÓN}

La revisión de la voz "The Bourbon Reforms" de Kenneth J. Andrien en las Oxford Bibliographies ${ }^{1}$ evidencia la omnipresencia y continua expansión de dicha categoría historiográfica para el estudio de la Monarquía católica,

1 Citamos a partir de la última modificación fechada el 25 de octubre de 2012. Kenneth J. Andrien, "The Bourbon Reforms", Oxford Bibliographies, 2012, http://www.oxfordbibliographies.com/view/document/obo-9780199766581/obo-9780199766581-0043.xml (consulta 27 de abril de 2016). 
en general, y, muy marcadamente, para el conjunto de las Indias pertenecientes a la Corona española, en el denominado siglo XVIII "largo" (c. 1700-1810). Ya se trate de visiones generales sobre lo acontecido en el mundo hispanoamericano durante el siglo XVIII, pasando por las manifestaciones regionales, los aspectos económicos, políticos, sociales e incluso culturales, decenas de trabajos jalonan un corpus historiográfico que parece indicarnos que el siglo XVIII en las Indias y las reformas borbónicas son términos sinónimos o, incluso, intercambiables para una misma realidad histórica ${ }^{2}$. Ante tamaña constatación cabe preguntarse cuándo, cómo y por qué hemos llegado hasta aquí.

El propósito de las siguientes reflexiones, enmarcadas en un ámbito específico, esto es, la historiografía institucional, económica y fiscal, es emprender posibles respuestas a dichos interrogantes, lo cual nos llevará desde apreciaciones de carácter general para el conjunto hispanoamericano hasta las puntualizaciones más acotadas para el espacio histórico denominado "virreinato de Nueva España". En este trayecto proponemos cuatro estaciones. En primer lugar, una somera revisión de la historiográfica mexicana del siglo XIX, dotada de un claro prisma nacionalista, en aras de ponderar la posible existencia de una "etapa" cualitativamente diferente en la evolución histórica de Nueva España durante el siglo XVIII, haciendo hincapié en los aspectos institucionales, económicos y fiscales. En segundo lugar, la reconstrucción genealógica de un concepto que, como vere-

2 Kenneth Andrien arranca su exposición integrando autores que atienden a épocas distintas y temas y enfoques muy variados (aunque la figura clave y el periodo central lo ocupa el reinado de Carlos III, 1759-1788) que, sin embargo, quedan subsumidos bajo la categoría "reformas borbónicas", en una secuencia que abarca desde trabajos publicados en la década de 1970 hasta los elaborados en la década de 2000. Historiadores entre los cuales destacan por su impacto historiográfico John Lynch, The Spanish American Revolutions, 1808-1826 (Londres: Weidenfeld and Nicholson, 1973); Jacques Barbier, "The Culmination of the Bourbon Reforms, 1787-1792", Hispanic American Historical Review, Vol. 57 (1977): 51-68; David A. Brading. "Bourbon Spain and Its American Empire", en The Cambridge History of Latin America. Vol. 1, Colonial Latin America, editado por Leslie Bethell (Cambridge: Cambridge University Press, 1984), 389-439; John Fisher. "Soldiers, Societies, and Politics in Spanish America", Latin American Research Review, Vol. 17.1 (1982): 217-222; Allan J. Kuethe. "La desregulación comercial y la reforma imperial en la época de Carlos III: Los casos de Nueva España y Cuba”, Historia Mexicana, Vol. 41.2 (1991): 265-292 o las diversas obras realizadas por Stanley y Barbara Stein, en especial la dedicada a España y Nueva España durante el reinado de Carlos III: Stanley J. Stein and Barbara H. Stein. Apogee of Empire: Spain and New Spain in the Age of Charles III, 1759-1789 (Baltimore: Johns Hopkins University Press, 2003). 
mos, estuvo dotado de dos formulaciones: el más extendido, las reformas borbónicas, o, el más acotado, el reformismo borbónico ${ }^{3}$. En tercer lugar, su enraizamiento en la historiográfica mexicana y mexicanista a partir de los estudios de historia económica y social desarrollados en la década de 1970, los cuales acabarían subsumiendo otras categorías historiográficas y denominaciones ${ }^{4}$. En cuarto lugar, el proceso de expansión de dicha terminología, hasta su completa "naturalización”. Un proceso que, en este caso, es equiparable al vivido en otras historiografías.

\section{LA HISTORIOGRAFÍA MEXICANA DEL SIGLO XIX: ¿CONSTITUYÓ EL SIGLO XVIII EN SÍ MISMO UNA ETAPA HISTORIOGRÁFICA?}

Nada más lapidario para los siglos de dominación de la Monarquía hispana sobre Nueva España que la valoración general que realizó el político, diplomático y publicista Lorenzo de Zavala en su Ensayo histórico de las revoluciones de México desde 1808 hasta 1830 (1831): "Como el tiempo anterior a los sucesos de 1808 es un periodo de silencio, de sueño y de monotonía, a excepción de algunos destellos que asomaban de cuando en cuando respirando la libertad, la historia interesante de México no comienza verda-

3 Si bien ambas denominaciones parecen ser intercambiables, es posible considerar también un contenido específico que iría desde las diferentes medidas adoptadas por las autoridades en los diversos niveles de gobierno y territorios durante el reinado de los Borbones en la Monarquía hispana (reformas borbónicas), lo que las asimilaría a cualquier acción de gobierno, hasta un uso más restringido en el cual las modificaciones introducidas (con mayor o menor éxito, no es el caso ahora entrar en esto) serían la plasmación no solo de un análisis de los problemas, sino también de la elaboración de un/os proyecto/s articulado/s de reforma. En este sentido restrictivo, numerosas medidas reactivas adoptadas ante la coyuntura quedarían fuera del "reformismo borbónico".

4 En un contexto donde primaban los estudios históricos de carácter económico y social (con una fuerte influencia del marxismo y la teoría de la dependencia), en el que todavía no se dejaba sentir el impacto de la nueva historia cultural y la renovación de la historia política, se articuló -como veremos- la categoría "reformas borbónicas". Cómo fue adoptada por los ámbitos historiográficos de la historia cultural y política, con posterioridad a los años iniciales de la década de 1970, en tanto evidencia naturalizada de la realidad histórica a explicar, es un estudio que cabe desarrollar en posteriores trabajos.

5 Para la conformación de la generación fundacional de historiadores mexicanos durante la primera mitad del siglo XIX, véase: Charles A. Hale El liberalismo mexicano en la época de Mora, 1821-1853 (México: Siglo XXI, 1972); Guillermo Zermeño Padilla, "Imparcialidad, objetividad y exactitud. Valores epistémicos en el origen de la historiografía moderna en México (1840-1910)", Historia y Grafía Vol. 20 (2003): 49. 


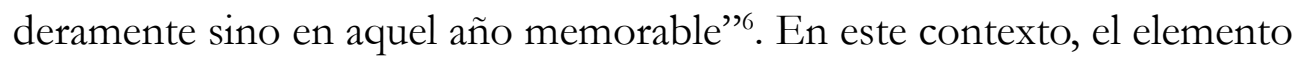
a destacar es la caracterización que realizó Zavala del periodo que cubre desde el siglo XVI hasta principios del siglo XIX como un todo, denominado "el sistema colonial establecido por el gobierno español", en el cual no cabía la búsqueda de una especificidad para el siglo XVIII o, en su caso, para la nueva dinastía gobernante entonces.

Como manifestación de una cierta modulación temporal, encontramos la obra México y sus revoluciones del sacerdote, político, diplomático y también publicista José María Luis Mora, aparecida en 1836, en la que destaca a efectos de nuestra exposición el apartado titulado la "administración de México bajo el régimen español”, en el que vemos desfilar diversas manifestaciones institucionales del gobierno de la Corona como eran la impartición de justicia, los consejos de la monarquía o la Real Hacienda, entre otros rubros; elementos que el autor pretendió exponer desde su establecimiento en las Indias. En este contexto, el Dr. Mora resaltó la introducción del régimen de intendencias y la figura de José de Gálvez en el campo del gobierno y la administración virreinales. Al respecto afirmó:

“[En] el año de 1776 [...] el gobierno español se propuso dar más regularidad a la división del territorio, para lo cual adoptó casi en su totalidad el sistema de intendencias que tan bien había probado en Francia. Don José de Gálvez, uno de los hombres de más mérito de la corte de Carlos III, fue el encargado de organizarlo para México, que había recorrido en clase de visitador algunos años antes".

Sin embargo, el autor consideró que la reforma no llegó a rendir plenamente sus frutos en la medida en que se vio trunca aunque, como contraparte, Mora apreció que la división territorial que se aplicó en Nueva España a partir de 1786 fue la base para la conformación del posterior régimen federal mexicano.

6 Lorenzo de Zavala, Ensayo histórico de las revoluciones de México desde 1808 hasta 1830 (México: Secretaría de la Reforma Agraria - CEHAM, 1981), tomo I, XXVII.

7 Lorenzo de Zavala, Ensayo histórico..., XXXV.

8 José María Luis Mora, "México y sus revoluciones”, en Obras completas José María Luis Mora, Vol. 4 (México: Instituto Mora/CONACULTA, 1994), 128. 
Mora no solo observó un cambio político-administrativo, también constató que España, "la menos adelantada de todas las naciones de Europa", experimentó una renovación al penetrar en ella "el espíritu filosófico del siglo XVIII". Una tarea en la cual su protagonista no sería otro que Carlos III: "Estaba reservado para el gobierno de Carlos III el causar un cambio total en las relaciones comerciales y políticas del nuevo continente con su metrópoli. Este sabio monarca se sobrepuso a las preocupaciones que habían detenido a sus predecesores" ". En este marco es notable el énfasis que hizo el autor de México y sus revoluciones en dos campos de dicho reinado: el comercio libre y la Hacienda, con valoraciones claramente disímiles. Así, en lo que atañe al comercio externo, el reinado de Carlos III era el compendio de todas las virtudes:

"[...] se aumentaron sin cesar las franquicias al comercio, libertándolo todos los días de alguna de las trabas que lo tenían encadenado; en él se sentaron principios fecundos en consecuencias benéficas que no pudieron en lo sucesivo atajarse; así es que en los reinados posteriores, a pesar de la nulidad e ineptitud de los que dirigían las operaciones del gabinete, lejos de volver atrás fue necesario caminar hacia adelante, pues nada pudo ya resistir el impulso dado"

De ahí que esta "época del comercio libre" pudiese ser considerada como "una de las más memorables en los anales de México". Sin embargo, en su tratamiento del Erario novohispano el autor incidía en dos aspectos. Por una parte, la conciencia de que la institución había sido reformada profundamente durante la visita de José Gálvez ("El sistema de hacienda que regía a México al hacerse de la Independencia era con muy corta diferencia el mismo que estableció el visitador don José de Gálvez [...]”) ${ }^{11}$ y, por la otra, la condena de una política que contradecía el libre comercio, en la medida en que bajo los dictados del visitador se impulsaron los estancos,

9 José María Luis Mora, "México y sus revoluciones...", 160.

10 José María Luis Mora, "México y sus revoluciones...”, 162.

11 José María Luis Mora, "México y sus revoluciones...”, 168. 
en especial, el del tabaco. Era la imagen contrapuesta de dos principios económicos: libertad de comercio y monopolio, de entre los cuales Mora se adhería claramente al primero.

Entre 1849 y 1852, el abogado, político, publicista y empresario Lucas Alamán presentó su Historia de Méjico en cinco volúmenes (Historia de Méjico: desde los primeros movimientos que prepararon su independencia en el año de 1808 hasta la época presente). En ella relató pormenorizadamente las instituciones de gobierno de los Austrias y los Borbones en Nueva España y consignó en diversos apartados del primer tomo de la obra los cambios que introdujo la nueva dinastía (sistema de leyes, forma de gobierno, ejército, la Real Hacienda, etc.).

Dotado de una visión conformada a partir de la esfera jurídica, Alamán efectuó una de las aportaciones más originales sobre el gobierno de los Borbones, en la medida en que las Leyes de Indias, que consideró como código propio, se habrían visto erosionadas por el gobierno absoluto implantado por la nueva dinastía, una de cuyas manifestaciones habría sido la Ordenanza de Intendentes de 1786, lo cual no obsta para que, en este caso, el autor considerase a dicho cambio institucional como una aportación positiva al establecer "un orden de administración" más "regular y sencillo" que el que le precedió:

"Este orden de cosas [la operatividad de las leyes y el Consejo de Indias] se observó con regularidad, durante el gobierno de los príncipes de la dinastía austriaca; mas desde que subió al trono la familia Borbón se procedió con un poder más absoluto, y sin respetar las trabas que los mismos monarcas se habían impuesto por medio de las leyes. Comunicábanse directamente con los ministros, sin pasar por el consejo, las providencias más importantes, y así se hizo con la Ordenanza de Intendentes, mandada guardar en 1786, por la que se estableció una nueva división de provincias y un orden de administración en ellas muy diverso y mucho más regular y sencillo que el que antes había. Se conservaron pues las formas establecidas por el código de Indias, pero el monarca se 
dispensaba de observarlas siempre que quería y todo pendía únicamente de su voluntad"12.

El régimen de intendencias no solo era positivo para el sistema de gobierno sino también como rectificación del gobierno absoluto. En este sentido Alamán señaló: “Todo este orden de cosas tan injusto y opresivo cesó con la Ordenanza de Intendentes, publicada por el ministro Gálvez en 4 de diciembre de 1786, limitada por entonces a solo la Nueva España pero que después se generalizó con convenientes modificaciones a toda la América española"13.

Según Alamán el edificio del gobierno de la monarquía española en las Indias había sido el resultado de una laboriosa acumulación de normas, muchas de ellas recopiladas, en las que la acción de los Borbones solo habría afectado a lo accesorio, guiados por principios por las "Luces" de la época:

"Los reyes de la casa de Austria-española habían levantado en dos siglos el laborioso edificio de las leyes recopiladas en el código de Indias: los soberanos de la familia de Borbón que ocuparon el trono español después de aquellos, guiados por los más ilustrados principios, hicieron en ellas grandes alteraciones y mejoras que recayeron sobre lo accesorio de la administración política y de hacienda, pero dejando siempre subsistente lo demás"14.

En la reconstrucción del pasado de Nueva España, claramente se aprecia en Alamán el rechazo a los cambios políticos emanados de ideas o principios abstractos. No en balde estamos ante un político que había virado al final de su vida hacia el conservadurismo, llegando incluso a cuestionar el principio de representación popular. Si algo tenía de bueno el gobierno de los Austrias es que había procedido sin rupturas, guiado por la experiencia. En la medida en que, según el autor, los Borbones habían afectado solo

12 Lucas Alamán, Historia de Méjico: desde los primeros movimientos que prepararon su independencia en el año de 1808 hasta la época presente (México, Imprenta de Victoriano Agüeros, 1883), tomo I, 77.

13 Lucas Alamán. Historia de Méjico..., tomo I, 105.

14 Lucas Alamán. Historia de Méjico..., tomo I, 113. 
a lo accesorio, la médula del sistema de gobierno indiano seguía vigente. Bajo esta óptica, el resultado de las reformas de los Borbones no solo es percibido de manera mucho más compleja por Alamán, sino que tuvo el matiz de considerar que las medidas aplicadas no habían quedaron circunscritas a las figuras de Carlos III y José de Gálvez, sino que las retrotrajo a la primera mitad del siglo XVIII. En este sentido afirmó (recuperando, posiblemente, los datos del Compendio de historia de la Real Hacienda de Nueva España de Joaquín Maniau de 1794) ${ }^{15}$ que con la llegada de los Borbones, sus ministros aplicaron reformas útiles como, por ejemplo, en los antiguos arrendamientos de rentas, las cuales se fueron colocando en administración. Como resultado de esta política, la corona había logrado en Nueva España una clara elevación de los valores de las rentas del Erario regio ${ }^{16}$.

Obras posteriores, como la del historiador, periodista y novelista español emigrado a México Niceto de Zamacois, Historia de Méjico, desde sus tiempos más remotos hasta nuestros días (1876-1882), en especial el tomo V, compuesto de 24 capítulos dedicados a los años de 1547 hasta finales del siglo XVIII, adoptaron un criterio que se volverá canónico en la historiografía nacionalista mexicana: la periodización a partir de los diversos gobernantes. Bajo este principio, en su obra se suceden los diversos virreyes y los acontecimientos más destacados ocurridos durante cada periodo de gobierno. Una secuencia narrativa en la que sobresalen para la primera mitad del siglo XVIII los gobiernos del marqués de Casafuerte (1722-1734) y el primer conde de Revillagigedo (1746-1755), virreyes que lograron aumentar notablemente las rentas reales ${ }^{17}$. Mención aparte ofrece del visitador Gálvez, sobre quien señaló que, en 1765 :

[...] le llegaron al visitador D. José de Gálvez las reales cédulas, concediéndole autoridad independiente del virrey y casi ilimitada. Allanadas de esta manera las dificultades que se suscitaron

15 Joaquín Maniau, Compendio de la historia de la Real Hacienda de Nueva España escrito en el año de 1794 (México: Sociedad Mexicana de Geografía y Estadística, 1914).

2816 Entre 1712 y el "final de siglo", el valor de las rentas había pasado de un monto cercano a los 3,068,000 pesos a los 20,000,000 de pesos. Lucas Alamán. Historia de Méjico..., tomo I, 117.

17 Niceto de Zamacois, Historia de Méjico, desde sus tiempos más remotos hasta nuestros días (Barcelona/México: Juan de la Fuente Parres, editor, 1878), Tomo V, 571. 
a su llegada entre el virrey y el visitador, entró éste a ejercer su empleo, desplegando una actividad y rectitud asombrosas [...] Al mismo tiempo que el activo visitador llenaba cumplidamente los deberes que le imponía el elevado cargo que el monarca le había dado, meditaba en la manera de aumentar las rentas reales"18.

Dicho interés por aumentar las rentas reales se plasmó en la implantación del estanco del tabaco. Zamacois destacó también que el visitador emprendió una serie de mejoras en varios ramos, por ejemplo, “[...] en administración de alcabalas, y no hubo ramo que no alcanzase importantes mejoras bajo la acertada dirección que les dio su mano"19, todo lo cual redundó en que la Real Hacienda de Nueva España experimentase una notable mejoría en el volumen de sus rentas.

En un prisma historiográfico que privilegiaba gobernantes y no políticas/ reformas, no es extraño que la Ordenanza de intendentes perdiese relevancia en la narración ante la figura del virrey II conde de Revillagigedo (1789-1794). De hecho, el tratamiento escueto que dio el autor al virrey Manuel Antonio Flores (1787-1789), a quien correspondió poner en marcha el nuevo régimen de gobierno, se contrapone la figura de Revillagigedo II como el compendio de todas las virtudes:

"El gobierno del conde de Revillagigedo dio una serie de disposiciones benéficas al país y a la corona, que han quedado consignadas en las luminosas páginas de la instrucción que dejó a su sucesor, marqués de Branciforte, y que deben ser estudiadas por los amantes a la buena administración [...]. Todo prosperaba bajo el paternal cuidado del ilustrado gobernante que cifraba su mayor ventura en la felicidad de sus gobernados"20.

Una prosperidad que había que atribuir sobre todo a la mejoría en la minería de metales preciosos, beneficiada por una acción reformista que había

18 Niceto de Zamacois, Historia de Méjico..., Tomo V, 597.

19 Niceto de Zamacois, Historia de Méjico..., Tomo V, 598.

20 Niceto de Zamacois, Historia de Méjico..., Tomo V, 684. 
redundado en el mayor "número de personas que últimamente se habían dedicado al laboreo de las minas" gracias "a la baja del precio del azogue, a la rebaja de la pólvora y a la exención de alcabalas" "21. Es decir, Zamacois consignó varios de los aspectos que apuntó posteriormente la historiografía del siglo XX como causas de los cambios acaecidos en la economía novohispana, aunque el eje promotor de la reforma se trasladó de José de Gálvez al segundo conde de Revillagigedo.

La obra cumbre de la historiografía nacionalista del siglo XIX, inscrita temporalmente en el gobierno de los generales Manuel González y Porfirio Díaz, fue el resultado de una tarea colectiva dirigida por el político, militar, periodista, escritor e historiador Vicente Riva Palacio titulada México a través de los siglos (1884-1889), en la que destacamos el libro tercero del tomo II, escrito por el propio Riva Palacio, compuesto de 15 capítulos dedicados al periodo que abarca de 1700 a 1799 (nótese el estricto apego a la cronología, tan propia del positivismo imperante en la época). En ella resalta como una de sus notas dominantes la ausencia de novedades profundas en el tratamiento y valoración de lo ocurrido en el Virreinato de Nueva España durante el siglo XVIII, respecto a lo apuntado por los autores anteriores, aunque sí se percibe en su exposición el despliegue de una capacidad mucho más prolija en términos de información. Sin embargo, el tratamiento homogéneo de los casi tres siglos de gobierno de la corona en Nueva España impide apreciar en el siglo XVIII un periodo o etapa cualitativamente diferenciado ${ }^{22}$.

En síntesis, algunos de los principales historiadores mexicanos o españoles que trabajaron en el siglo XIX sobre la historia de Nueva España, asimilada en términos conceptuales nacionalistas a México, tuvieron en general conciencia de que en el siglo XVIII se habían presenciado novedades relevantes a partir de la acción de gobierno de los ministros y virreyes de la Casa de Borbón. Un planteamiento que, sin embargo, fue mucho más acusado en las obras de la primera mitad del siglo XIX, por su combinación de temas, enfoques y personajes, mientras que en las que

21 Niceto de Zamacois, Historia de Méjico..., Tomo V, 686.

22 Vicente Riva Palacio, México a través de los siglos (México: Editorial Cumbre S.A., 1974), tomo II. El Virreinato. 
se elaboraron en el último cuarto del ochocientos primó el tratamiento homogéneo de lo acontecido al quedar las exposiciones constreñidas por un modelo compartimentado de la historia de Nueva España a partir de los diversos gobernantes que se sucedieron ${ }^{23}$. A pesar de todo, el registro de variaciones en las formas de gobierno de la monarquía (ministros versus consejos) y de la administración (régimen de intendencias), las reformas en la Real Hacienda y en la minería y en el comercio externo, presididas por ideas nuevas al abrigo de la Ilustración, así como la preeminencia de monarcas como Felipe V y, sobre todo, Carlos III, junto a ciertos gobernantes novohispanos como los virreyes Casafuerte, Revillagigedo I o Revillagigedo II, u otros agentes de las políticas de la Corona, como sucedió con el visitador general José de Gálvez, todos ellos estuvieron presentes en la historiografía decimonónica. Sin embargo, su aparición no implicaba que conformasen unos eventos que pudiesen ser subsumidos ni como un todo ni en partes bajo una categoría historiográfica que los agrupase, de ahí que no constituyesen un fenómeno, fase o etapa cualitativamente diferenciada en el devenir del Virreinato de Nueva España.

23 Cabe señalar que la irrupción de una nueva dinastía en el gobierno de las Indias no generó en la historiografía mexicana decimonónica tratamientos encontrados en términos valorativos como sí ocurrió en la española donde se pasó de un visión positiva de las medidas reformistas adoptadas por los nuevos gobernantes de la monarquía hispana, con la obra de Modesto Lafuente Historia general de España (1850) como emblema, a una condena genérica de toda la dinastía tras la revolución democrática de 1868, con la obra de Eduardo Palacio España desde el primer Borbón hasta la revolución de septiembre (18681869) como canon interpretativo. En este sentido, la historia de los Borbones hispanos sirvió para un ajuste de cuentas entre las diversas facciones política españolas del convulso siglo XIX. Benoît Pellistrandi, "Los Borbones entre historia y opinión. Los historiadores del siglo XIX y su visión de la instauración borbónica", en Pablo Fernández Albaladejo (ed.). Los Borbones. Dinastía y memoria de nación en la España de siglo XVIII (Actas del coloquio internacional celebrado en Madrid, mayo 2000) (Madrid: Marcial Pons Historia/Casa de Velázquez, 2002), 627-644. Una valoración que, sin embargo, el regeneracionismo imbuido del Desastre colonial de 1898 volvería a alterar en la medida en que contrapuso la constitución "morbosa" de los Austrias a los intentos de "sanación" desplegados por los Borbones. Pablo Fernández Albaladejo, "Presentación”, en Pablo Fernández Albaladejo (ed.). Los Borbones. Dinastía y memoria de nación en la España de siglo XVIII (Actas del coloquio internacional celebrado en Madrid, mayo 2000) (Madrid: Marcial Pons Historia/Casa de Velázquez, 2002), 7-11. Para un balance historiográfico crítico con la visión elaborada en torno a los Borbones hispanos, con Carlos III como figura central, consultar: Francisco Sánchez-Blanco. El Absolutismo y las Luces en el reinado de Carlos III (Madrid: Marcial Pons Historia, 2002). Una crítica que el autor extiende a las categorías historiográficas despotismo ilustrado o reformismo borbónico ya que, según el autor, "no hacen más que camuflar la inseguridad y la indecisión a la hora de plantear el problema fundamental de la definición o de la descripción restrictiva y excluyente de la Ilustración y distinguirla de otros fenómenos culturales o estéticos coetáneos". Francisco Sánchez-Blanco. El Absolutismo y las Luces en el reinado de Carlos III (Madrid: Marcial Pons Historia, 2002), 9. 


\section{GENEALOGÍA DE UN CONCEPTO: LAS REFORMAS BORBÓNICAS}

En nuestra revisión sobre el origen del concepto historiográfico "las reformas borbónicas" 24 , hemos podido rastrear su uso historiográfico en la década de 1950. En este sentido, la obra Aproximación a la Historia de España de Jaime Vicens Vives, publicada en 1952 constituye un ejemplo notable ${ }^{25}$. Se trataba de un historiador formado durante el franquismo que tuvo una rápida apertura a la denominada escuela de los Annales, quien realizó algo sorprendente para la época. En una obra de síntesis y, en gran medida de divulgación, procedió a englobar la historia de la España del siglo XVIII bajo un epígrafe titulado "El reformismo borbónico", tras haber tratado en un apartado previo sobre "El vuelco de Hispania y la bancarrota de la política de la dinastía de los Habsburgo". Así, en la introducción al mencionado capítulo, señaló:

\section{"Bourbon reforms}

In the course of one century, from 1700 to 1808, the new Bourbon dynasty carried out a series of thoroughgoing reforms. Some grew out of the need to liquidate the Hapsburg regime. Others were the product of arbitrary ministerial action, inspired by European examples during the age of Enlightened Despotism. The majority of the reforms attempted to remedy the acute domestic problems created by the recuperation of Spanish vitality, evident in an increase in population an in a rapid acceleration of trade and manufacturing" 26 .

Estas medidas tuvieron en el cambio administrativo y de gobierno algunas de sus más acusadas manifestaciones; algo que era evidente para un his-

24 Entendidas como una categoría historiográfica que pretende delimitar un periodo y dar explicación a un fenómeno histórico y no como la mera referencia a "acciones" o "medidas" adoptadas por los gobiernos de la corona y el virreinato durante el siglo XVIII en respuesta a eventos internos y/o externos, ya que, en este caso, su presencia es constatable, como vimos, desde la historiografía del siglo XIX.

32 Jaime Vicens Vives, Aproximación a la Historia de España (Madrid: Centro de Estudios Históricos Internacionales, 1952).

26 Se cita por su edición inglesa, publicada en California en 1967: Jaime Vicens Vives. Approaches to the History of Spain (Berkeley: California University Press, 1967), 114. 
toriador que conocía sobradamente el impacto causado por la Guerra de Sucesión y los Decretos de Nueva Planta de Felipe V en el principado de Cataluña ${ }^{27}$.

Fue una acción reformista que tuvo en la figura de Carlos III el eje y emblema de una política presidida por el denominado Despotismo ilustrado:

"Because a large part of the desire for reform was polarized under the aegis of Charles III, this monarch has been converted into the paradigm of Enlightened Despotism in Spain. [...] Charles clearly gave the country a tone of political modernity and economic well-being; at the same time he provided a sense of power in the maritime wars that he waged against England in defence of Spain's American empire. The first war ended adversely (1761-1763) but in the second war, in which Charles supported the English colonist in the North America in their struggle for independence (1779-1783), the outcome was advantageous" 28 .

Transformaciones que, sin embargo, generaron tensiones sociales, además de enfrentamientos entre lo que consideró un "rígido racionalismo" y el "carácter hispánico histórico" (una concepción esta más próxima al vitalismo historiográfico de raíz orteguiana que a la historia social francesa) ${ }^{29}$.

Es decir, Vicens Vives aportó una categoría historiográfica plenamente desarrollada (temporalidad, actores sociales, principios unificadores de las diversas medidas adoptadas, contradicciones generadas con motivo de la acción reformista, etc.) que se resumía en los siguientes aspectos: a) el reformismo como manifestación de un programa político: el despotismo ilustrado; b) el protagonismo, si bien no único, de la figura de Carlos III, y

27 "Catalonia became a filed for experimentation with the new procedures of a unified administration: the Captaincy General, the provincial high court (audiencia), the intendant, and royally appointed chief magistrates in the towns (corregidores). The purpose of all these measures was to insure that the province paid for the army od occupation, witch, in turn, was responsible for supervising the collection of the single tax (catastro)". Jaime Vicens Vives, Approaches to the History..., 114-115.

29 Jaime Vicens Vives, Approaches to the History..., 120. 
c) las reformas como causa generadora de tensiones y contradicciones que traían aparejadas un peligro constante de explosión o revuelta social (ej. los motines de mediados del siglo XVIII por problemas agrarios, a la par que se decretaba la libertad de granos. Una protesta encauzada por ciertas élites de la época contra un ministro del rey, el marqués de Esquilache, como emblema del denominado "despotismo ministerial") ${ }^{30}$. Por lo tanto, un contenido historiográfico que, como veremos después, se aproxima bastante a los planteamientos desplegados por numerosos autores de las décadas posteriores ${ }^{31}$.

Una atención especial merece la obra de Luis Navarro García, profesor de la Universidad de Sevilla, en la medida en que hizo también un empleo temprano de la categoría "reformas borbónicas", concretamente en 1959, en su estudio sobre el régimen de intendencias en las Indias ${ }^{32}$. No solo eso, atribuyó una temporalidad específica al fenómeno, ubicándolo a partir de mediados del siglo XVIII. Al respecto, señaló:
"El ilustrado siglo XVIII no se abre para las Indias españolas sino con muchos años de retraso.
Sólo pasada la mitad de esta centuria, cuando ya las reformas borbónicas han arraigado en la Península, empiezan a notarse allí los efectos de la expansión de los moldes institucionales [...]"33.

A esta cronología, con un punto de arranque muy preciso -el final de la

30 Para rastrear el origen y características de las críticas al gobierno ministerial de los Borbones en la monarquía hispana consultar: María Victoria López Cordón, "Secretarios y secretarías en la Edad Moderna: de las manos del príncipe a relojeros de las monarquías", Studia Histórica. Historia Moderna Vol. 15 (1996): 107-131 y Anne Dubet, La Hacienda real de la Nueva Planta (1713-1726), entre el fraude y el buen gobierno. El caso de Verdes Montenegro (Madrid/México: Fondo de Cultura Económica, 2015).

31 Esta obra tuvo una amplia difusión en los medios académicos europeos y norteamericanos, como pone de manifiesto la reseña publicada por Anthony Luttrell en 1964. Anthony Luttrell, Reviews: "Aproximación a la Historia de España. Segunda edición (Universidad de Barcelona: Centro de Estudios Históricos Internacionales. Serie A: estudios, I) Barcelona, Spain: Editorial Teide, 1960, paper, p. 244", Speculum. A Journal of Medieval Studies Vol. 39 No 2 (april, 1964): 355-357. Una reseña en la que se comentaban también otras obras y encuentros académicos, como el IV y VI congreso de Historia de la Corona de Aragón.

32 Luis Navarro García, Las intendencias en Indias (Sevilla: EEHA-CSIC, 1959).

33 Luis Navarro García, Las intendencias en Indias..., 1. 
guerra de los Siete Años-, Navarro García añadió su promotor, Carlos III, así como su principal instrumento, José de Gálvez, tanto en su faceta de visitador general de los tribunales y el Erario Regio de Nueva España como en la de secretario del Despacho de Indias:

"Hay una fecha clave: 1763. Es a partir del fin de la guerra de los Siete Años cuando la atención de los gobernantes se fija decididamente en los amplios dominios de España [...] Bajo la suprema dirección de Carlos III, una etapa fundamental en el gobierno de las Indias la constituye el periodo de doce años en que José de Gálvez ocupa la Secretaría encargada de los negocios de aquellas dilatadas regiones" 34 .

Lo que para Vicens Vives era un fenómeno que arrancaba necesaria e inmediatamente tras la Guerra de Sucesión (con base en los decretos de Nueva Planta), en Navarro García se retrasaba a la época de la introducción de las intendencias en América (La Habana, 1764; Caracas, 1776; Buenos Aires, 1782; Perú, 1784; Nueva España, 1786) ${ }^{35}$. Resulta notable pues, que ambas obras estableciesen una etapa de la historia de la Monarquía hispana asociada a la nueva dinastía reinante con base en su accionar reformista.

En este mismo contexto historiográfico de la década de 1950, aparecieron las obras de dos autores que hicieron de la historia económica y fiscal hispanoamericana del siglo XVIII su objeto de estudio: Guillermo Céspedes del Castillo y Eduardo Arcila Farías. Si bien ninguno de ellos empleó entonces el término "reformas borbónicas", su análisis se centró en las novedades económicas y fiscales promovidas durante el setecientos, con la figura de Carlos III como hito, una vez más, a destacar. En el caso de Céspedes del Castillo, en su estudio de 1953 sobre la "Reorganización de

34 Luis Navarro García, Las intendencias en Indias..., 1.

35 Si bien la obra de John Lynch sobre el sistema de intendencias en el Río de la Plata es prácticamente coetánea al estudio de Luis Navarro García (1958), la categoría que empleó Lynch fue la de reorganización colonial con dos hitos: la creación del virreinato y la introducción de la intendencia. Acciones de gobierno presididas por el llamado "despotismo ilustrado", con la figura de Carlos III como emblema de una reforma "desde arriba". John Lynch, Spanish Colonial Administration, 1782-1810. The Intendant System in the Viceroyalty of the Río de la Plata (London: University of London, 1958). 
la Hacienda virreinal peruana", se aportó una temporalidad muy precisa para el desempeño del Erario Regio peruano, a partir de la acción reformista, la cual dividió en tres etapas:

"En general, puede decirse que las reformas hacendísticas en el Perú, se centran en el periodo 1773-1785. Todos los años anteriores, diríase que constituyen una etapa de preparación, de espaciadas medidas fragmentarias y parciales. En 1773, con la creación de la Aduana por el virrey Amat, se inician novedades de verdadero alcance, que culminarán en 1780-1785 con la etapa más fecunda de la visita general, desempeñada sucesivamente por Areche y Escobedo. Concluida esta, a partir de 1785, adviene un periodo de menos relieve, caracterizado por la simple consolidación de las reformas ya implantadas, que en algún caso se completan o alteran parcialmente" 36 .

Más relevante, si cabe, será la figura del Eduardo Arcila Farías, en su obra titulada El siglo ilustrado en América. Reformas económicas del siglo XVIII en Nueva España, publicada en Caracas en $1955^{37}$, en la cual vemos aparecer, entre otros temas, ideas económicas de raíz francesa (que califica como "neomercantilismo"), los proyectos de compañías comerciales nacionales o los cambios en la administración y el erario, con José de Gálvez, de nueva cuenta, como emblema ${ }^{38}$, todo lo cual le permitió concluir:

"Fue durante el siglo XVIII cuando Nueva España llegó al más elevado punto de su evolución económica [...]. Este desenvolvimiento fue de considerables proporciones, sobre todo en la segunda mitad del siglo, a consecuencia de la política de Carlos III" $" 39$.

36 Guillermo Céspedes del Castillo, "Reorganización de la Hacienda virreinal peruana", Anuario del Derecho español, tomo XXIII (1953), 331.

37 Eduardo Arcila Farías, El siglo ilustrado en América. Reformas económicas del siglo XVIII en Nueva España (Caracas: Edición del Ministerio de Educación, 1955). [Publicado en México, sin el título "El siglo ilustrado en América" por SEP setentas, en 1974].

38 "Reformas en la administración. El periodo de las grandes reformas fiscales en la Nueva España se inicia con la llegada del visitador Gálvez, quien, en 1765, trajo instrucciones para hacer una revisión general de las cuentas y de toda la administración de la Hacienda”. Eduardo Arcila Farías, Reformas económicas del siglo XVIII en Nueva España Vol. II (México: SEP setentas, 1974), 163-164.

Eduardo Arcila Farías, Reformas económicas..., 182. 
Lo destacable es que la conexión de la categoría de Jaime Vicens Vives, la temporalidad y protagonistas de Luis Navarro García y la expansión temática de Céspedes del Castillo y Arcila Farías, que no limitaron la acción reformista del gobierno a la introducción del sistema de intendencias en América, arroja todos los ingredientes que hacen reconocibles los usos historiográficos de la categoría "reformas borbónicas" que se implantaría y extendería a partir de la década de $1960^{40}$.

\section{IMPLANTACIÓN Y EXPANSIÓN DE LA CATEGORÍA REFORMAS BORBÓNICAS EN LA HISTORIOGRAFÍA INSTITUCIONAL, ECONÓMICA Y FISCAL SOBRE Nueva España}

Dos referencias son recurrentes en la historiografía institucional, económica y fiscal de Nueva España cuando se procede al abordaje de las reformas borbónicas: Miners and Merchants in Bourbon Mexico, 1763-1810 de David A. Brading, publicada en $1971^{41} \mathrm{y}$, en menor medida, Die Einführung des Intendantensystems in Neu-Spanien im Rabmen der allgemeinen Verwaltungsreform der spanischen Monarchie im 18. Jabrhundert (La introducción del sistema de intendencias en Nueva España en el contexto de la reforma administrativa general de la monarquía española en el siglo XVIII) de Horst Pietschmann, publicada en $1972^{42}$.

Lo más llamativo es que ninguna de estas dos obras empleó propiamente la categoría "reformas borbónicas" (o en su defecto, el "reformismo borbónico") a lo largo de su exposición para determinar la existencia de una etapa específica de la historia institucional o económico-social de Nueva España. Ni la "revolución en el gobierno" de Brading, ni la "reforma administrativa general" de Pietschmann asumieron las formulaciones creadas en la década de 1950. De hecho, la incorporación de la obra de Pietschmann tiene que ver mucho más con el cambio de nombre que recibió

40 Un ejemplo de ello sería la recopilación de textos y personajes que efectuó Troy S. Floyd en 1966, titulada: The Bourbon Reformers and Spanish Civilization; Builders or Destroyers? (Boston: Heath, 1966).

41 David A. Brading, Miners and Merchants in Bourbon Mexico, 1763-1810 (Cambridge: Cambridge University Press, 1971). La edición en español, que es desde donde citamos, es: Mineros y comerciantes en el México borbónico (1863-1810) (México: FCE, 1975).

42 Fue defendida como tesis en 1969 y publicada en Colonia en 1972. Citamos a partir de la edición en español publicada muchos años después. Horst Pietschmann, Las reformas borbónicas y el sistema de intendencias en Nueva España. Un estudio político administrativo (México: FCE, 1996). 
su trabajo al traducirse y publicarse en México en 1996, en donde "La introducción del sistema de intendencias" se convirtió en "Las reformas borbónicas y el sistema de intendencias", recogiendo lo que en ese momento (la década de 1990) ya era una moneda de uso corriente.

No es que los temas estuviesen ausentes, en realidad eran casi los mismos que los aparecidos en la década de 1950 o, incluso antes, si arrancamos con los estudios de la década de 1920 sobre las intendencias en América ${ }^{43}$, o los efectuados por José María Ots Capdequí y Clarence H. Haring en las décadas de 1930-1940, en los cuales vemos desfilar, respectivamente, en sus trabajos sobre El Estado Español en las Indias (1946) ${ }^{44}$ y The Spanisch Empire in America $(1947)^{45}$, muchos de los aspectos que serían tratados en las décadas de 1950 y 1960, con el añadido de que el tema del régimen de intendencias y la figura de Carlos III eran los aspectos centrales en sus argumentaciones, aunque cabe precisar que se trataba de obras que tenían una amplitud e intereses que ultrapasaban claramente el reformismo dieciochesco. Lo que sucede es que lo que en el exiliado español eran "las grandes reformas políticas y administrativas del siglo XVIII" bajo la égida del "despotismo ilustrado", en el hispanista quedaban resumidas bajo la categoría "las reformas coloniales".

Retornando al objetivo de investigación de David A. Brading, decíamos que su interés no estaba en las reformas borbónicas sino, según el autor, en el México borbónico: "Al escribir este libro, mi propósito ha sido definir primeramente un periodo histórico que yo llamo México Borbónico, y después describir sus características principales"46. Un objetivo que obtuvo la siguiente formulación:

43 Una obra clave en esta temática fue la de Lillian Estelle Fisher sobre el sistema de intendencias en Hispanoamérica, en la que presentó y realizó la glosa en inglés de la ordenanza de intendentes de Nueva España de 1786, así como su comparación con la de Buenos Aires. Lillian Estelle Fisher, The Intendant System in Spanish America (Berkeley: University of California Press, 1929).

44 José María Ots Capdequí, El Estado español en las Indias (México: FCE, 1941).

45 Clarence H. Haring. The Spanish Empire in America (New York: Oxford University Press, 1947).

46 David A. Brading, Mineros y comerciantes en el México borbónico (1763 en página 28 1863-1810) (México: FCE, 1975), 8. Se trata de una afirmación presente en un prefacio firmado en Guanajuato-Berkeley entre 1966-1969. De hecho, gran parte de la redacción de la obra se efectuó en la Berkeley-UCLA, donde dejó depositados los "Three essays on Bourbon Mexico, 1763-1810: Guanajuato, Mexico and Berkeley, Calif.: typescript, 1966-1969 (v.1 - The Revolution in Government: Miners and Merchants; v. 2 - Guanajuato)". 
"El México borbónico, si se nos permite designar así al periodo de 1763 a 1810, tuvo su origen en la exitosa colaboración de un gobierno despótico pero ilustrado, con un grupo vigoroso de comerciantes capitalistas y millonarios mineros. En gran medida, el éxito de las reformas económicas del gobierno dependió del espíritu de empresa y del capital de aquellos hombres de nego$\operatorname{cios}{ }^{\prime 4}$.

Es decir, una etapa caracterizada por una acción de gobierno enérgica (bajo una categoría reformulada del despotismo ilustrado, aderezado con elementos económicos mercantilistas a la sombra de Colbert y con la obra de José del Campillo y Cossío como guía) y el protagonismo de dos grupos sociales ("comerciantes capitalistas" y "millonarios mineros") que no se podía corresponder con los momentos previos ya que "los estadistas de la nueva dinastía borbónica no intentaron seriamente reformar el desordenado y anticuado patrimonio de la Casa de Austria hasta las décadas medias del siglo XVIII"48. Pero no solo se asistió a la aparición de un "nuevo Estado", el borbónico que "nació, como moriría más tarde, en medio de la violencia y del derramamiento de sangre"49. En este sentido, el Bourbon Mexico de Brading era una versión acotada en lo temporal y sustantiva en términos historiográficos de los diversos "Bourbon" (Perú, México, España, etc.) que proliferaron en la historiografía anglosajona e hispanoamericana ${ }^{50}$.

Si estos eran los contenidos generales, los elementos definitorios del Bourbon México en la fiscalidad remitían a la creación de monopolios y una nueva administración de las rentas, con la ordenanza de intendentes como cénit de dicha política:

"La innovación principal que introdujeron los Borbones fue la imposición del monopolio real sobre el tabaco, los juegos de car-

47 D. A. Brading, Mineros y comerciantes..., 53.

48 D. A. Brading, Mineros y comerciantes..., 46-47.

49 D. A. Brading, Mineros y comerciantes..., 49.

50 En el caso de Perú consultar: Carlos Daniel Valcárcel, "Perú borbónico y emancipación", Revista de Historia de América Vol. 50 (1960): 35. 
tas y la pólvora, y en el empleo de funcionarios asalariados para que administraran estos monopolios y para que recaudaran las alcabalas. [...] El impulso de expansión y revitalización de la burocracia llegó a su clímax en 1786 con el nombramiento de unos doce intendentes" ${ }^{\prime \prime}$.

Y, sin embargo, la obra de David A. Brading fue considerada como la base historiográfica de las "reformas borbónicas". Una faceta que, según nuestro punto de vista, cabe atribuir a tres autores: Claude Morin, Enrique Florescano e Isabel Gil.

Por lo que atañe al historiador canadiense, este realizó un reseña (cabría añadir "muy crítica") ${ }^{52}$ de la obra de Brading, publicada en la revista Historia Mexicana en 1973, que ponderó y alabó su arquitectura y erudición, así como el que el autor plantease "problemas a través del vaivén entre análisis pormenorizados e ideas e hipótesis sugerentes.” No obstante, lo más relevante a efectos de nuestro recorrido es que, al describir el trabajo y sus precedentes, afirmó:

"No se trata de una monografía, sino de tres estudios temáticos relacionados. La primera parte titulada 'La revolución en el gobierno' procura valorar las reformas iniciadas con la visita de Gálvez y medir el impacto del sistema de intendencias, clave del reformismo borbónico. Por ser un tema que ya ha suscitado una oleada de investigaciones (Lynch, Navarro García, para citar los más destacados), podría temerse la redundancia. No sucede asî" ${ }^{53}$.

51 David A. Brading, Mineros y comerciantes..., 52. Muchas de las formulaciones que realizará Brading en el desglose de estos elementos contienen un orden de causalidad o temporalidad no se avienen con su definición del "Bourbon México" (1763-1810).

52 "Nuestra discrepancia radicará más bien en el nivel teórico. A pesar de su solidez, la obra adolece de la falta de un marco de referencia que permita ordenar los hechos e interpretar los fenómenos en función de una clave. El análisis no se sustenta en una teoría general ni se propone contribuir a su formulación. En ausencia de una visión orgánica que conciba los fenómenos como partes de un sistema o de una estructura, se escapa el sentido de ciertos comportamientos". A lo que añadirá: "El historiador debe deshacerse de una concepción puramente empírica de su tarea. Es preciso que la erudición sea al servicio de un planteamiento teórico, porque la teoría es la condición básica para el desarrollo de una ciencia". Claude Morin, "Examen de libros", Historia Mexicana Vol. 23 No. 1 (89) (jul.-sep., 1973): 189.

53 Claude Morin, "Examen de libros", Historia Mexicana..., 176. La cursiva es nuestra. 
Es decir, Claude Morin conectó la obra de Brading con la estela de trabajos que desde los años 50 del siglo XX había emparentado el estudio del régimen de las intendencias del reinado de Carlos III con el reformismo borbónico ${ }^{54}$.

Ese mismo año, Enrique Florescano e Isabel Gil publicaron el primer volumen de las Fuentes para la historia económica de México ${ }^{55}$, en el marco de un programa editorial del Instituto Nacional de Antropología e Historia (INAH), en el que "se propone aportar materiales básicos para el estudio del desarrollo y composición de la economía mexicana en el pasado”. En este programa, las obras tendrían dos características:

"En primer lugar, todos los volúmenes planteados para la primera parte de la serie se dedicarán al periodo 1750-1821. Este lapso abarca un ciclo completo de la economía colonial: el que comienza hacia 1740-1750 con una gradual recuperación de la población y de las principales actividades económicas; alcanza entre 1790-1805 su mayor auge, en el ciclo y en toda la historia de la economía colonial, y finalmente entra en un proceso de decaimiento progresivo en los 15 años últimos del periodo. Es importante estudiar esta época porque antecede al movimiento de independencia y porque es aún una de las menos conocidas en sus aspectos económicos y sociales.

En segundo lugar, el mismo crecimiento económico de la época y las reformas administrativas ordenadas por los Borbones generaron una documentación abundantísima sobre casi todos los procesos económicos..." 56 .

$54 \mathrm{Al}$ respecto, resalta que en el número anterior de la revista Historia Mexicana Enrique Florescano realizase una reseña breve, claramente informativa, en el que no apareció ningún rastro del término "reformismo borbónico". Enrique Florescano, "Examen de libros", Historia Mexicana Vol. 22 No. 3 (87) (ene.-mar., 1973): 420.

55 Enrique Florescano e Isabel Gil (comps.). Descripciones económicas generales de Nueva España, 1784-1817 (México: SEP/INAH, 1973).

56 Florescano y Gil, Descripciones económicas..., 7. Las cursivas son nuestras. 
Una formulación como la anterior contaba ya con los dos trazos que perfilarían la categoría historiográfica: la temporalidad (1750-1821, aunque se arranca en la década de 1740) y su contenido (el crecimiento económico y la reforma institucional de los Borbones); unas ideas que Enrique Florescano reiteraría en la "advertencia" que insertó en la obra titulada Controversia sobre la libertad de comercio en Nueva España 1776-1818, publicada en 1975 por el Instituto de Comercio Exterior de México ${ }^{57}$, un trabajo en el que "las reformas de los Borbones" cobraron una preeminencia notable:

"A mediados del siglo XVIII Carlos III y sus ministros ilustrados, presionados por la pujante amenaza del poder inglés y la decadencia de la economía española, ensayaron varias reformas de tipo político, administrativo y económico, que buscaban los siguientes fines: en lo político, recuperar para la corona los poderes y prerrogativas de gobierno que la dinastía de los Habsburgo había delegado en grupos y corporaciones, tales como los Consulados de comerciantes, la Iglesia, los hacendados y otros grupos. En lo administrativo, las reformas de los Borbones tendían a crear un Estado moderno, con instituciones más eficientes y un equipo de administradores y funcionarios dependientes del poder real y bien adiestrado en el servicio público. En lo económico, las reformas de los Borbones se orientaron a restablecer la decadente economía española y a tratar de que las colonias americanas financiaran en forma más decidida la economía metropolitana"58.

El compendio de estas formulaciones (D. A. Brading, C. Morin, E. Florescano, I. Gil) se produjo en una obra de síntesis que tuvo un gran impacto historiográfico: la Historia general de México, publicada por El Colegio de México en 1976. En el tomo II de dicha obra apareció el capítulo de Enrique Florescano e Isabel Gil titulado "La época de las reformas borbónicas y el crecimiento económico, 1750-1808" 59 , en el que se observan plena-

57 Enrique Florescano, "Advertencia”, en Controversia sobre la libertad de comercio en Nueva España 1776-1818, Enrique Florescano y Fernando Castillo (comps.) (México: Instituto de Comercio Exterior, 1975), tomo I, 13-21.

58 Enrique Florescano, “Advertencia...”, 18-19. Las cursivas son nuestras.

59 Enrique Florescano e Isabel Gil, "La época de las reformas borbónicas y el crecimiento económico, 1750-1808”, Historia General de México (México: El Colegio de México, 1976), tomo II, 183-301. 
mente integrados a la categoría "reformas borbónicas" los elementos que aportó David A. Brading en Mineros y comerciantes. Dos párrafos fueron claves en la formulación de los autores del capítulo. El primero definió el periodo a tratar:

El siglo XVIII no comienza en la Nueva España con el fin cronológico del siglo XVII, por más que en 1700 España y su vasto Imperio colonial conozcan el cambio dinástico que sustituye a los Habsburgos con los Borbones. Quienes estudian los procesos económicos quizá aventurarían fijar el cambio de siglo hacia 1730 o 1740, cuando se inicia un claro ascenso de la población, la minería, el comercio y la agricultura. Por otra parte, si una época se delimita por los rasgos específicos que la hacen diferente de las precedentes y de las posteriores, entonces habría que encerrar el siglo XVIII entre 1760 y 1821, porque en estas fechas ocurren las transformaciones mayores que dan a esta época una personalidad propia. Durante esos años se ensaya la reforma política y administrativa más radical que emprendió España en sus colonias, ocurre el ange económico más importante que registra la Nueva España, con la consecuencia de que la sociedad colonial padece desajustes y desgarramientos internos, se abre a las ideas que recorren las metrópolis y busca nuevas formas de expresión a los intereses sociales, económicos, políticos y culturales que han crecido en su seno" ${ }^{\circ 0}$.

El segundo párrafo aportó los trazos básicos de dicho reformismo, según la formulación realizada por David A. Brading en el capítulo sobre "la revolución en el gobierno" ${ }^{1}$, presente en su obra Mineros y comerciantes:

"Las reformas que a partir de mediados del siglo XVIII comenzaron a implantar los Borbones en todo el Imperio español buscaban remodelar tanto la situación interna de la península como sus relaciones con las colonias. Ambos propósitos respondían a una nueva concepción del Estado que consideraba como prin-

60 Florescano y Gil, "La época de las reformas...", 185. Las cursivas son nuestras.

61 David A. Brading, Mineros y comerciantes..., 55-132. 
cipal tarea absorber los atributos del poder que había delegado en grupos y corporaciones y asumir la dirección política, administrativa y económica del reino. Los principios básicos de esta nueva política se identifican con las del llamado 'despotismo ilustrado': regalismo o predominio de los intereses del monarca y del Estado sobre los individuos y corporaciones; impulso de la agricultura, industria y comercio con sistemas racionales; desarrollo del conocimiento técnico y científico, y difusión de las artes. La aplicación de este programa demandaba de una nueva organización administrativa del Estado y nuevos funcionarios. Para lo primero se adaptó el sistema de intendentes o gobernadores provinciales que se había instaurado en Francia; y para lo segundo, se hizo un extenso reclutamiento de nuevos hombres en las filas de la clase media ilustrada y entre los extranjeros. En cuanto a América, [...] la Guerra de los Siete Años [...], apresuró la adopción de una política que se venía pregonando desde 1743 [...]. Sin embargo, la política que los Borbones decidieron aplicar en las Indias a partir de 1760 incluía propósitos más amplios: reforma del aparato administrativo de gobierno, recuperar los poderes delegados a las corporaciones, reforma económica y, sobre todo, mayor participación de la colonia en la financiación de la metrópoli’’22.

Lo que vino después fue la expansión sin límites. Una especie de big bang de la categoría reformismo borbónico/reformas borbónicas (en ocasiones, como términos intercambiables) aplicable a cualquier momento o aspecto de la vida política, económica, social e, incluso, cultural de Nueva España durante el siglo XVIII largo (1700-1810) en el que interviniese la acción de los poderes públicos, en consonancia con otras historiografías. Hitos de este proceso, tanto para Nueva España como para otros espacios de la Monarquía española, fueron las aportaciones que efectuaron destacados historiadores anglosajones e hispanoamericanos entre finales de la década de 1970 y la década de 1990, todo lo cual acabó ampliando y 
naturalizando el empleo de dicho concepto, el cual pasó a ser sinónimo de cualquier iniciativa gubernamental ${ }^{63}$.

Una de las plasmaciones más acrisoladas de esta situación se encuentra en un libro colectivo coordinado por Agustín Guimerá, publicado en 1996, titulado sintomáticamente El reformismo borbónico. Una visión interdisciplinar, en el que se agrupan trabajos de numerosos autores en torno a una categoría que, a la altura de la década de 1990, se había vuelto omnipresente. Fueron los casos de John Lynch, Pedro Pérez Herrero, John Fisher o José Miguel Delgado Barrado, por centrarnos únicamente en los textos más relacionados en la obra con el cambio político-administrativo y las reformas mercantiles y fiscales ${ }^{64}$. Si hasta los años 90 del siglo XX, todos esos contenidos y enfoques habían podido circular de forma autónoma y con diversas formulaciones - el reformismo colonial, la segunda conquista, el despotismo ilustrado, las reformas borbónicas, etc.-, ahora podían ser etiquetados como facetas de un genérico reformismo borbónico hispano. No solo eso, la obra coordinada por A. Guimerá propuso el anclaje de dichas reformas en un ámbito más general, concretamente europeo. Así, en la introducción a la obra se afirmó: "El libro [...] ha elegido una singladura específica: el debate científico, espinoso e inacabado, sobre el denominado reformismo borbónico en el mundo hispánico, expresión del absolutismo ilustrado del siglo XVIII europeo" ${ }^{65}$.

63 Ejemplos relevantes de ello serían los trabajos referidos tanto a Nueva España como a otros espacios del Imperio español, elaborados por J. Barbier Jacques Barbier. "The Culmination of the Bourbon Reforms, 1787-1792”, Hispanic American Historical Review Vol. 57 (1977): 51 y Jacques Barbier, A. Reform and Politics in Bourbon Chile, 1755-1796 (Ottawa: University of Ottawa Press, 1980], C. Archer [Christon I. Archer. The Army in Bourbon Mexico, 1760-1810 (Albuquerque: University of New Mexico Press, 1977)], los diversos estudios presentados en 1982 en el 44 Congreso Internacional de Americanistas, celebrado en Manchester, en el que Lyman L. Johnson y Susan M. Socolow elaboraron una relatoría en torno a un simposio titulado "The Bourbon Reforms in South America" y por el cual desfilaron John J. TePaske, Juan Carlos Garavaglia, Lyman L. Johnson, S. Socolow, Miguel Izard, Kendall Brown y Anthony McFarlane, en trabajos que hacía referencia a los Virreinatos del Perú, Río de la Plata y Nueva Granada.

64 Agustín Guimerá (ed.), El reformismo borbónico. Una visión interdisciplinar (Madrid: CSIC/Alianza Editorial, 1996).

65 Agustín Guimerá, "Introducción”, Agustín Guimerá (ed.), El reformismo borbónico... Un absolutismo ilustrado que era definido según los parámetros de Hamish M. Scott. Al respecto consultar: Hamish M. Scott. Enlightened Absolutism. Reform and Reformers in Later Eighteenth-Century Europe (Ann Arbor: University Michigan Press, 1990). 


\section{Conclusiones}

El recorrido historiográfico que hemos efectuado entre los siglos XIX y XX permite apreciar varias situaciones. En primer lugar, la percepción de que la instauración de una nueva dinastía gobernante en el trono español en el siglo XVIII tuvo un tratamiento desigual en la historiografía mexicana del siglo XIX que iba desde un análisis indiferenciado con el resto de siglos de gobierno virreinal (Zavala, Zamacois, Riva Palacio), hasta la percepción de que en dicha centuria se introdujeron novedades relevantes en el sistema de gobierno y la fiscalidad virreinales (Mora, Alamán). Sin embargo, en ningún caso se llegó a ponderar la existencia de una etapa cualitativamente diferenciada en el denominado genéricamente en la época como "sistema colonial", una categoría desarrollada a partir de la obra La Riqueza de las Naciones de A. Smith (1776). En segundo lugar, se constata cómo la conformación de la categoría reformas borbónicas en la historiografía mexicana (que llegó a ser empleada como sinónimo del reformismo borbónico) fue el resultado de la confluencia de numerosos trabajos de historia institucional, económica y fiscal elaborados entre las décadas de 1950 y 1960, referidos al ámbito español (Vicens Vives) e hispanoamericano (Navarro García, Céspedes del Castillo, Arcila Farías, Valcarcel), con fuertes raíces en la historia política e institucional de los años 30 y 40 del siglo XX (Ots y Capdequí, Haring), que no guardaban relación directa con la historiografía decimonónica mexicana. En tercer lugar, se aprecia que la consolidación de dicha categoría historiográfica se produjo en la década de 1970, según la cual el periodo 1760-1810 habría supuesto para el virreinato de Nueva España una etapa cualitativamente diferenciada, al presenciarse un intenso proceso de reforma institucional ("la revolución en el gobierno" de D. A. Brading o "el sistema de intendencias" de H. Pietschmann), asociado a un periodo de fuerte crecimiento económico y agudización de las tensiones sociales, así como de descontento, ante lo que se habría considerado como una intensa política extractiva de la Corona, la cual habría empleado para ello uno de sus principales instrumentos de gobierno: La Real Hacienda de Nueva España; una formulación que tuvo en los trabajos de E. Florescano e I. Gil uno de sus productos más acabados.

La historia posterior es la constatación del éxito historiográfico de dicha periodización y categorización, pero también de su cuestionamiento. En 
este sentido, durante los últimos años hemos asistido a un escrutinio cuidadoso de sus rasgos principales que, por ejemplo, ha generado discrepancias en el sentido unidireccional de las reformas (v.g. la idea de que el reforzamiento del poder fiscal de la Corona solo se podía obtener mediante la generalización del sistema de administración directa de las rentas), ha llevado al abandono de una temporalidad que todo lo remitía a lo ocurrido tras la Guerra de los Siete Años, ha mostrado la inconsistencia en la secuencia que iba, y en ese orden, de las reformas peninsulares, primero, a las reformas en las Indias, después, ha dado entrada a nuevos agentes como protagonistas de las reformas (es el caso de las corporaciones mercantiles y mineras o de actores privados individuales), lo que supone cuestionar la idea de que todo se debió a los proyectos e iniciativas de notables ministros de Indias, virreyes o visitadores, etc. Sin embargo, el desglose de estos aspectos amerita un trabajo específico que dé cuenta de los orígenes historiográficos de las nuevas percepciones que se están desarrollando en torno a las reformas borbónicas y que, llegado el caso, pueda llevar a un severo cuestionamiento de su utilidad como herramienta de interpretación de los cambios institucionales, económicos y fiscales ocurridos durante el setecientos en las Indias occidentales ${ }^{66}$.

\section{Bibliografía}

Alamán, Lucas. Historia de Méjico: desde los primeros movimientos que prepararon su independencia en el año de 1808 hasta la época presente. México: Imprenta de Victoriano Agüeros, 1883-1885, 5 tomos.

66 Algunos ejemplos de este revisionismo se pueden apreciar en los trabajos siguientes: Michel Bertrand, Grandeza y miseria del oficio. Los oficiales de la Real Hacienda de la Nueva España, siglos XVII y XVIII. México: FCE, El Colegio de Michoacán/Centro de Estudios Mexicanos y Centroamericanos/Embajada de Francia/Instituto de Investigaciones Dr. José María Luis Mora/Centro de Investigación y Docencia Económicas, 2011; Anne Dubet, La Hacienda Real de la Nueva Planta (1713-1726), entre el fraude y el buen gobierno. El caso de Verdes Montenegro. Madrid/México: Fondo de Cultura Económica, 2015; Iván Escamilla González, Los intereses malentendidos: el Consulado de Comerciantes de México y la monarquía española, 1700-1739 (México: Instituto de Investigaciones Histórica-UNAM, 2011); Adrian J. Pearce, The origins of Bourbon reform in Spanish South America, 1700-1763 (New York, NY: Palgrave Macmillan, 2014); Ernest Sánchez Santiró, Corte de Caja. La Real Hacienda de Nueva España y el primer reformismo fiscal de los Borbones (1720-1755). Alcances y contradicciones (México: Instituto Mora, 2013). 
Arcila Farías, Eduardo. El siglo ilustrado en América. Reformas económicas del siglo XVIII en Nueva España. Caracas: Edición del Ministerio de Educación, 1955.

Arcila Farías, Eduardo. Reformas económicas del siglo XVIII en Nueva España. México: SEP setentas, 1974, 2 vols.

Archer, Christon I. The Army in Bourbon Mexico, 1760-1810. Albuquerque: University of New Mexico Press, 1977.

Barbier, Jacques. "The Culmination of the Bourbon Reforms, 1787-1792". Hispanic American Historical Review Vol. 57 (1977): 51-68.

Barbier, Jacques A. Reform and Politics in Bourbon Chile, 1755-1796. Ottawa: University of Ottawa Press, 1980.

Bertrand, Michel. Grandeza y miseria del oficio. Los oficiales de la Real Hacienda de la Nueva España, siglos XVII y XVIII. México: FCE, El Colegio de Michoacán/Centro de Estudios Mexicanos y Centroamericanos/Embajada de Francia/Instituto de Investigaciones Dr. José María Luis Mora/Centro de Investigación y Docencia Económicas, 2011.

Brading, D. A. Mineros y comerciantes en el México borbónico (1863 en página 19, 1763-1810). México: FCE, 1975.

Brading, David A. "Bourbon Spain and Its American Empire". En The Cambridge History of Latin America. Vol. 1, Colonial Latin America, editado por Leslie Bethell. Cambridge: Cambridge University Press, 1984, 389-439.

Céspedes del Castillo, Guillermo. "Reorganización de la Hacienda virreinal peruana", Anuario del Derecho Español, tomo XXIII (1953), 329-369.

Dubet, Anne. La Hacienda Real de la Nueva Planta (1713-1726), entre el fraude y el buen gobierno. El caso de Verdes Montenegro. Madrid/ México: Fondo de Cultura Económica, 2015.

Escamilla González, Iván. Los intereses malentendidos: el Consulado de Comerciantes de México y la monarquía española, 1700-1739. México: Instituto de Investigaciones Históricas-UNAM, 2011.

Fernández Albaladejo, Pablo. "Presentación". En Los Borbones. Dinastía y memoria de nación en la España de siglo XVIII (Actas del coloquio internacional celebrado en Madrid, mayo 2000), editado por Pablo Fernández Albaladejo. Madrid: Marcial Pons Historia/Casa de Velázquez, 2002, 7-11. 
Fisher, John. "Soldiers, Societies, and Politics in Spanish America". Latin American Research Review Vol. 17.1 (1982): 217-222.

Fisher, Lillian Estelle. The Intendant System in Spanish America. Berkeley: University of California Press, 1929.

Florescano, Enrique. "Examen de libros". Historia Mexicana Vol. 22 No. 3 (87) (ene.-mar., 1973): 420-422.

Florescano, Enrique. "Advertencia”. En Controversia sobre la libertad de comercio en Nueva España 1776-1818, compiladores Enrique Florescano y Fernando Castillo. México: Instituto de Comercio Exterior, 1975, tomo I, 13-21.

Florescano, Enrique e Isabel Gil (comps.). Descripciones económicas generales de Nueva España, 1784-1817. México: SEP/INAH, 1973.

Florescano, Enrique e Isabel Gil. "La época de las reformas borbónicas y el crecimiento económico, 1750-1808”, Historia General de México. México: El Colegio de México, 1976, tomo II, 183-301.

Floyd, Troy S. The Bourbon Reformers and Spanish Civilization; Builders or Destroyers? Boston: Heath, 1966.

Guimerá, Agustín (ed.). El reformismo borbónico. Una visión interdisciplinar. Madrid: CSIC/Alianza Editorial, 1996.

Guimerá, Agustín. "Introducción”. El reformismo borbónico. Una visión interdisciplinar, editado por Agustín Guimerá. Madrid: CSIC/Alianza Editorial, 1996, 9-33.

Hale, Charles A. El liberalismo mexicano en la época de Mora, 1821-1853. México: Siglo XXI, 1972.

Haring, Clarence H. The Spanish Empire in America. New York: Oxford University Press, 1947.

Kuethe, Allan J. "La desregulación comercial y la reforma imperial en la época de Carlos III: Los casos de Nueva España y Cuba". Historia Mexicana Vol. 41.2 (1991): 265-292.

López Cordón, María Victoria. "Secretarios y secretarías en la Edad Moderna: de las manos del príncipe a relojeros de las monarquía”. Studia Histórica. Historia Moderna Vol. 15 (1996): 107-131.

Luttrell, Anthony. Reviews: "Aproximación a la Historia de España. Segunda edición (Universidad de Barcelona: Centro de Estudios Históricos Internacionales. Serie A: estudios, I.) Barcelona, Spain: Editorial Teide, 1960, paper, p. 244”, Speculum. A Journal of Medieval Studies Vol. 39. 2 (april, 1964): 355-357. 
Lynch, John. Spanish Colonial Administration, 1782-1810. The Intendant System in the Viceroyalty of the Rio de la Plata. London: University of London, 1958.

Lynch, John. The Spanish American Revolutions, 1808-1826. Londres: Weidenfeld and Nicholson, 1973.

Maniau, Joaquín. Compendio de la historia de la Real Hacienda de Nueva España escrito en el año de 1794. México: Sociedad Mexicana de Geografía y Estadística, 1914.

Mora, José María Luis. "México y sus revoluciones”. En Obras completas, José María Luis Mora. México: Instituto Mora/CONACULTA, 1994, 8 vols.

Morin, Claude. "Examen de libros". Historia Mexicana Vol. 23 No. 1 (89) (jul.-sep., 1973): 176-190.

Navarro García, Luis. Las intendencias en Indias. Sevilla: EEHA-CSIC, 1959.

Ots y Capdequí, José María. El Estado español en las Indias. México: FCE, 1941.

Pearce, Adrian J. The origins of Bourbon reform in Spanish South America, 1700-1763. New York, NY: Palgrave Macmillan, 2014.

Pellistrandi, Benoit. "Los Borbones entre historia y opinión. Los historiadores del siglo XIX y su visión de la instauración borbónica”. En Los Borbones. Dinastía y memoria de nación en la España de siglo XVIII (Actas del coloquio internacional celebrado en Madrid, mayo 2000), editado por Pablo Fernández Albaladejo. Madrid: Marcial Pons Historia/Casa de Velázquez, 2002, 627-644.

Pietschmann, Horst. Las reformas borbónicas y el sistema de intendencias en Nueva España. Un estudio político administrativo. México: FCE, 1996.

Riva Palacio, Vicente (dir.). México a través de los siglos. México: Editorial Cumbre S.A., 1974, V tomos.

Sánchez-Blanco, Francisco. El Absolutismo y las Luces en el reinado de Carlos III. Madrid: Marcial Pons Historia, 2002.

50 Sánchez Santiró, Ernest. Corte de caja. La Real Hacienda de Nueva España y el primer reformismo fiscal de los Borbones (1720-1755). Alcances y contradicciones. México: Instituto Mora, 2013. 
Scott, Hamish M. Enlightened Absolutism. Reform and Reformers in Later Eighteenth-Century Europe. Ann Arbor: University Michigan Press, 1990.

Stein, Stanley J. and Barbara H. Stein. Apogee of Empire: Spain and New Spain in the Age of Charles III, 1759-1789. Baltimore: Johns Hopkins University Press, 2003.

Valcárcel, Carlos Daniel. "Perú borbónico y emancipación”. Revista de Historia de América 50 (1960): 315-438.

Vicens Vives, Jaime. Aproximación a la Historia de España. Madrid: Centro de Estudios Históricos Internacionales, 1952.

Vicens Vives, Jaime. Approaches to the History of Spain. Berkeley: California University Press, 1967.

Zamacois, Niceto de. Historia de Méjico, desde sus tiempos más remotos hasta nuestros días. Barcelona/México: Juan de la Fuente Parres, editor, 1876-1882, XVIII tomos.

Zavala, Lorenzo de. Ensayo histórico de las revoluciones de México desde 1808 hasta 1830. México: Secretaría de la Reforma Agraria-CEHAM, 1981, 2 tomos.

Zermeño Padilla, Guillermo. "Imparcialidad, objetividad y exactitud. Valores epistémicos en el origen de la historiografía moderna en México (1840-1910)”. Historia y Grafía Vol. 20 (2003): 49-83.

Para citar este artículo: Sánchez Santiró, Ernest. "Las reformas borbónicas como categoría de análisis en la historiografía institucional, económica y fiscal sobre Nueva España: orígenes, implantación y expansión", Historia Caribe Vol. XI No. 29 (Julio-Diciembre 2016): 19-51. DOI: http:// dx.doi.org/10.15648/hc.29.2016.3 